\title{
Family Voices: Life for Family Carers of People with Intellectual Disabilities in Ireland
}

\author{
Darren D. Chadwick*, Hasheem Mannan ${ }^{\dagger}$, Edurne Garcia Iriarte*, Roy McConkey ${ }^{\S}$, Patricia O’Brien", Frieda Finlay \\ Anne Lawlor* and Gerry Harrington* \\ *School of Applied Sciences, The University of Wolverhampton, Wolverhampton, UK; ${ }^{\dagger}$ Centre for Global Health, Trinity College Dublin, Dublin, \\ Ireland; ${ }^{\ddagger}$ National Institute for Intellectual Disability, Trinity College Dublin, Dublin, Ireland; ${ }^{\S}$ Institute of Nursing Research, University of \\ Ulster, Belfast, UK; "Centre for Disability Studies, The University of Sydney, Sydney, NSW, Australia
}

Accepted for publication 19 October 2012

Background Families in Ireland remain the main providers of support for people with Intellectual disabilities, and the aim of this study was to map their life experiences whilst involving their family members as co-researchers.

Materials and Method This qualitative, participatory study involved 10 focus groups attended by 70 parents and siblings of people with intellectual disabilities. Data were analysed using thematic analysis.

Results Caring for a family member with intellectual disabilities was found to be a dynamic and adaptive process. The well-being of the family and the challenges they face throughout their lives was the central theme identified. This was affected by: the availability of appropriate supports for families and having to advocate for them, communication and relationships

\section{Introduction}

The majority of people with intellectual disabilities in Ireland are supported by family care givers (Kelly et al. 2010). Recent research has suggested that despite a considerable amount of investment between 1999 and 2009 few more independent living arrangements were developed in Ireland (Kelly \& McConkey 2012). In the current climate of economic austerity, cuts in disability services are occurring in Ireland as elsewhere (Health Services Executive 2012). It is possible that reduced placement availability and service support may lead to more people remaining in the care of their families and families having greater difficulty accessing services. It is important to learn more about the lives, needs and supports of these family carers. with services and professionals, the availability of information and attitudes towards disability and governmental support.

Conclusions Strategies are suggested as to how services can better support family carers in Ireland in their role. These include families being provided with flexible and timely support for families at critical times; being offered services, support, entitlements and information without having to fight for them; knowing that their family member with intellectual disabilities is well cared for, listened to and provided with opportunities to develop and be part of the community; and carers being shown respect, listened to and involved in decisions.

Keywords: family carers, focus groups, intellectual disability, Ireland, participatory research, wellbeing
A recent review has indicated that more research is needed to better understand the changes across the lifespan of families and the relationship of family members to the school, community, workplace, out of home residence and respite providers of the family member with intellectual disabilities (Families Special Interest Research Group of IASSID 2012). This expanded knowledge could enable human services to move to being of service to families and persons with intellectual disabilities rather than giving a service to families (Fergusson \& O’Brien 2005). By understanding more about families, services will be better informed and can become better equipped to provide services that meet their needs.

Family lives have been extensively researched outside of Ireland. With regard to services, previous studies 
have found that despite their high social and economic needs (Sloper \& Beresford 2006), families believe that they: (i) do not receive an adequate amount or quality of services (Shearn \& Todd 1997; Sardi et al. 2008); (ii) do not get sufficient information about and from services (Summers et al. 2007; Sardi et al. 2008); (iii) are constantly fighting for better services (Sardi et al. 2008; Yannamani et al. 2009) and (iv) are not adequately listened to, respected or involved by services (Shearn \& Todd 1997; Dobson et al. 2001; Summers et al. 2007; Yannamani et al. 2009). Studies have also reported that families of people with intellectual disabilities often take on more responsibilities than other families, and carers may become isolated and lonely (Dobson et al. 2001), stressed (Beresford 1995; Browne \& Bramston 1998; Hoare et al. 1998), depressed (Lambrenos et al. 1996; Olsson \& Hwang 2001) and exhausted (Shearn \& Todd 1997; Green 2007).

Many of their needs as carers appear to remain largely unmet (Sloper \& Beresford 2006). Similarly, existing Irish literature suggests that families of people with intellectual disabilities experience many disappointments and struggles with services (McConkey 2005; Kenny \& McGilloway 2007; Power 2008; McConkey et al. 2010) but that service support can benefit family functioning (Merriman \& Canavan 2007).

According to a recent review (Families Special Interest Research Group of IASSID 2012), despite such challenges, families nevertheless report typical levels of well-being (Baker et al. 2005; Glidden \& Jobe 2006; Olsson et al. 2008) and positive feelings around parenting a child with intellectual disabilities (Scorgie \& Sobsey 2000; Blacher \& Baker 2002; Hastings \& Taunt 2002; Ylvén et al. 2006; Green 2007).

To date though, there have been few attempts to examine the personal insights and experiences of Irish families of people with an intellectual disabilities which may vary from that reported in other countries due to cultural differences and the reliance on voluntary rather than statutory organizations for the provision of services. (Welshman et al. 2005). Additionally, no Irish studies have employed participatory research approaches or trained family members as co-researchers. Turnbull et al. (1998) suggests a number of benefits of these approaches including: increasing the relevance and rigour of the research; reducing logistical problems, for example in recruiting participants; increasing the uptake of the research results and enhancing empowerment. Participatory research is underpinned by the belief that research with people should be democratic and participative (Ladkin 2007). It is research with people rather than on them (Reason \& Bradbury 2006), and it aspires to reduce the gap between researchers and those that the research is intended to benefit (McTaggart 1991; Turnbull et al. 1998).

Hence this study had two main aims. First to gain an insight into the support needs of family carers across Ireland, which can be used to inform future service and policy developments in Ireland. Second, to assess the feasibility and impact of including family members as co-researchers.

\section{Method}

\section{Approach}

The research formed part of a national study which sought to answer the question: 'What is life like for families who have a member with an intellectual disability?' A participatory approach was used in this descriptive qualitative study (e.g., Turnbull et al. 1998), which employed focus groups to gather the data. Researchers and family members acted as co-researchers throughout the course of investigation. Ethical approval for this project was gained from the School of Social Work and Social Policy ethics committee, Trinity College Dublin.

\section{Recruitment of the co-researchers and focus group participants}

Invitations were distributed to 3000 families across Ireland. Families were identified via voluntary organizations including the 63 member organizations of the National Federation of Voluntary Bodies as well parent associations such as the National Parent \& Sibling Alliance; 22Q11; Inclusion Ireland and Down Syndrome Ireland. The organizations forwarded the invitation letter to their members with a self-addressed stamped envelope for families to reply, indicating their willingness to participate in the study either as coresearchers and/or as respondents.

Responses were received from 630 families from all 26 counties in the Republic of Ireland. Maximum variation sampling was used based on preliminary background information collected from the respondents to try and ensure that a range of families with differing characteristics were included in the study; specifically the views and experiences of families based in rural and urban locations, who had family members with intellectual disabilities of differing ages and with differing levels of support needs. Based on this strategy, 
120 family members were invited to participate in the focus groups and of these, 70 attended on the day to take part in one of 10 focus groups. Few non-attending family members gave reasons as to why they did not attend, but of those that did, most reported having other family commitments that prevented them from attending. Despite the maximum variation sampling, by not inviting 410 other families, it is possible that we may have excluded important information about the lives of other families in Ireland. However, a second phase of the study addressed this concern (Chadwick et al. 2010).

Additional background information was collected from participants prior to the focus groups, about their education, employment, family income and the severity of their family member's cognitive impairment. Table 1 presents the participants' demographic characteristics and those of their sons, daughters or siblings with intellectual disabilities.

\section{Training the co-researchers}

The training workshop on being a co-researcher took place after the focus groups and 44 participants volunteered to take part. The workshop offered a 'hands-on' opportunity to lead a subsequent focus group as a co-researcher and guidance on dealing with potentially difficult situations that may arise. At its conclusion, participants were asked if they would be interested and available to co-facilitate a focus group for the project at another site and 10 people volunteered of whom four became co-researchers in the present study (one father and three mothers). Between them they cofacilitated 7 of the 10 focus groups held as no one had been trained to co-facilitate the first focus group and for two other focus groups, no co-researching family member was available (see Walmsley \& Mannan 2009). Families who did not want to continue as a coresearcher were not questioned as to why. However, the most common reasons mentioned were that they did not have time available or mobility to travel. Data were not collected to determine the differences between those families who did not wish to continue from those who did. However, reflecting on this process the researchers involved felt that they had relatively mature, experienced, financially solvent, campaigning and confident family co-researchers working alongside them.

\section{Conducting the focus groups}

The 10 focus groups were held in nine different locations across Ireland and varied in size between 3
Table I Demographic and background characteristics of the participant family members and of the family member with intellectual disabilities $(n=70)$

\begin{tabular}{|c|c|c|}
\hline Variable & $n$ & $\%$ \\
\hline \multicolumn{3}{|c|}{$\begin{array}{l}\text { Relationship to family member with intellectual disabilities } \\
(n=70)\end{array}$} \\
\hline Mother & 50 & 71.4 \\
\hline Father & 15 & 21.4 \\
\hline Sister & 5 & 7.1 \\
\hline \multicolumn{3}{|l|}{ Age $(n=68$ reported) } \\
\hline $30-39$ & 6 & 8.8 \\
\hline $40-49$ & 25 & 36.8 \\
\hline $50-59$ & 17 & 25.0 \\
\hline $60-69$ & 20 & 29.4 \\
\hline \multicolumn{3}{|l|}{ Education ( $n=64$ reported) } \\
\hline Second level & 25 & 39.1 \\
\hline Non-degree & 23 & 35.9 \\
\hline Degree & 12 & 18.8 \\
\hline Masters & 4 & 6.3 \\
\hline \multicolumn{3}{|l|}{ Employment ( $n=66$ reported) } \\
\hline Full time & 19 & 28.8 \\
\hline Part time & 17 & 25.8 \\
\hline Not employed/full time carers & 30 & 45.5 \\
\hline \multicolumn{3}{|c|}{ Age of family member with intellectual disabilities $(n=69)$} \\
\hline $0-6$ & 6 & 8.7 \\
\hline $7-18$ & 18 & 26.1 \\
\hline $19-29$ & 22 & 31.9 \\
\hline $30-39$ & 20 & 29.9 \\
\hline $40+$ & 3 & 4.3 \\
\hline \multicolumn{3}{|l|}{ Severity of intellectual disability $(n=70)$} \\
\hline Mild & 26 & 37.1 \\
\hline Moderate & 27 & 38.6 \\
\hline Severe & 17 & 24.3 \\
\hline \multicolumn{3}{|c|}{$\begin{array}{l}\text { Living arrangement of the family member with intellectual } \\
\text { disabilities }(n=69)\end{array}$} \\
\hline Home & 53 & 76.8 \\
\hline $\begin{array}{l}\text { Residential services (includes community } \\
\text { group homes, residential centres, psychiatric } \\
\text { hospitals and intensive placements) }\end{array}$ & 15 & 21.7 \\
\hline Independent & 1 & 1.5 \\
\hline
\end{tabular}

and 10 participants. With the exception of the first focus group, which was held in Dublin, the locations, venues, dates and times for all subsequent focus groups were selected by family co-researchers. A semi-structured focus group guide provided general direction for the focus group discussion based around 'grand tour' questions (Poston et al. 2003); these included: (i) Tell us about what life is like as a family for you; (ii) Tell us about instances when things have gone really well for you in terms of 'family support' and 'family needs'; 
(iii) Tell us about instances that have been especially tough within the context of 'family support' and 'family needs'; (iv) If you had a choice what one change would you make for your family to have a good time?; (v) What would be the one thing you would do differently for your family to have a good time? These questions were developed prior to the involvement of the family co-researchers; however, they were reviewed and agreed by family co-researchers prior to data collection and the semi-structured, conversational nature of focus groups allowed the family co-researchers who led the focus groups to ask additional probes.

\section{Data analysis}

With the consent of participants, all focus groups were recorded and transcribed verbatim by a researcher. The transcribed data were then analysed by the researchers using thematic analysis (Braun \& Clarke 2006) facilitated by qualitative data analysis software; NVIVO, v.8 (2008). This process incorporated familiarization with the data, searching and coding of the text to identify themes within the data, and reviewing and confirming final themes. It is also seemed that data saturation had been reached in that no new main themes emerged in the later focus groups. The extracted themes were taken back to the family co-researchers for discussion and further refinement; hence they were involved in the reviewing and confirming stage of the analysis process.

In addition, a member of the research team independently conducted an inquiry audit trail into the trustworthiness of the study, loosely following the process laid out by Halpern (1983, cited in Lincoln \& Guba 1985) including secondary coding of the data, triangulation of investigators analysing the data and member checking (Lincoln \& Guba 1985; Shenton 2004). Triangulation involved the first and second authors separately familiarizing themselves with the recordings and transcriptions of the data, then coding the data. During this process the two researchers updated and discussed extracted themes and associated quotations with the other researcher and family co-researchers during meetings until agreement was reached about the final organizing themes. Member checks involved discussions with the family co-researchers and their involvement in the reviewing and confirming stage of the data analysis process. Subsequently, two member checking events were held in Dublin and Galway, at which the findings were summarized. At these, participants were asked if findings accurately represented their views. Family participants who attended indicated that organizing themes extracted did represent key issues in their lives.

\section{Findings}

Four main inter-related global themes were extracted from the focus group data and are described in Table 2.

\section{Family well-being: variations and challenges across the lifespan}

The central theme that appeared to be influenced by and to influence the other themes was the fluctuating lives of families and the challenges that they faced. Participant family members often spoke about having both good and bad times in their lives and how these impacted upon family well-being. This linked both to

Table 2 Thematic domains extracted from the focus groups along with their definitions

\begin{tabular}{|c|c|}
\hline Theme & Definition \\
\hline $\begin{array}{l}\text { Family well-being: variations and challenges } \\
\text { across the lifespan }\end{array}$ & $\begin{array}{l}\text { Life transitions and other factors that challenge the family and affect the well-being of } \\
\text { the family across the lifespan }\end{array}$ \\
\hline Support and advocacy & $\begin{array}{l}\text { Being adequately and appropriately supported and the advocacy activities families } \\
\text { undertake. Includes support by community, services, professionals, family \& friends } \\
\text { and the fighting families do to access services and supports for their family }\end{array}$ \\
\hline Communication and accessing information & $\begin{array}{l}\text { Communication with services and professionals and the availability of information to } \\
\text { the family about entitlements, services and supports. It incorporates being consulted, } \\
\text { kept informed, listened to and respected for their expertise by services \& } \\
\text { professionals }\end{array}$ \\
\hline Attitudes and governance & $\begin{array}{l}\text { Societal, community, service and professional, and governmental attitudes towards } \\
\text { the family and people with disabilities and the ways that governmental } \\
\text { bureaucracies, policies and funding issues that impact on the family's lives }\end{array}$ \\
\hline
\end{tabular}


daily ups and downs in life and to life events and changes that happened as members of the family got older and went through life transitions. The challenges this presented included being overprotective and feeling unable to allow the person to become more independent.

"... we as parents are without a shadow of a doubt, overprotective. And it's only right that we should be protective. But there's times when you have to give them space." (Father, Clare)

Some younger carers had concerns about the future lives of their children once they had left school. Some were worried that without planning, services they presently had would reduce or disappear once their child entered adulthood. Others had been through this transition and were now struggling to help their family find employment. These concerns highlighted the tension between the aspirations of families and service planning and drivers.

"There isn't any planning ... It's also the interaction between the service telling you what their plan is and what planning can we make?" (Mother, Cork)

Some families described the move out of the family home and times when their family member started to use respite and day services. Some deemed this necessary for the well-being of the rest of the family, whilst others reported feeling guilty at the prospect of relinquishing responsibility for the everyday care and support of their child.

"He's been with the (Christian) brothers ... full time since he left school at 18. ... Looking back we were on a guilt trip many a time, my wife and myself, were you know what are we doing with our son? Putting him away." (Father, Cork)

Nonetheless all families commented on the happiness, joy, pride and inspiration they gained from their family member with intellectual disabilities. People expressed optimism about their lives and the life of their relative. Some, however, remarked that putting on a brave face was a duty carers felt towards the rest of the world.

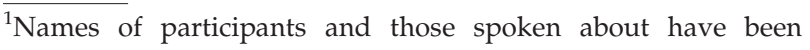
anonymized by using only initials.
}

"S__ 1 is quite independent, and you know that's our life and that's it, and I mean she's the centre of our life really, we're just mad about her" (Mother, Dublin)

But tensions and frustrations in family relationships were also discussed. These included the negative impact having a sibling with intellectual disabilities has on other children, reducing the amount of attention and time they receive from their parents. A few parents mentioned the strain having a child with intellectual disabilities had on their marriage and relationships with extended family. Alongside this though, parents also commented on the positive relationships between family members, particularly the relationships people had with their siblings.

"Because my husband, well he started accepting my son but it was a struggle before. It was a bad struggle. ... But he damaged my marriage but this is not about my marriage, this is about my son. But the influence that a disabled child can have on any relationship ..." (Mother, Cork)

"I am a single parent since they were very young, they were a year and two years when my husband left so, and they were like twins because they were so close in age. ... My daughter always had to make way for him. He needed all the attention." (Mother, Kildare)

Family carers wanted their family member with intellectual disabilities to be happy with their life and well supported. A central concern was that their family member with intellectual disabilities was in good health and got health care when they needed it. Physical and mental health problems and managing the family member's behaviour posed particular challenges.

"one of the biggest worries is depression with him and trying to get services for him." (Mother, Kildare)

Families had concerns and fears about their family member with intellectual disabilities developing romantic and sexual relationships. Some spoke about how it would be inappropriate for their family member due to their reduced level of cognitive and social development, whilst others were more accepting of the possibility of such relationships. When it was discussed as a possibility, it was mainly behaviour found in the early stage of relationships which was described. 
"That's alright (holding hands), but it's when it would go further, I would not ... I would be very, very, very strong against that, because they are not able." (Mother, Clare)

"I mean my brother would be assessed with the mental ability of an 8 year old but I mean I was asked straight out if I would allow him to have a sexual relationship. I said, no, would you allow an 8 year old to do that, and that's what my brother's mental ability is. But I've been made feel like when I said no, I was made feel a little bit like I was curtailing his rights" (Sister, Clare)

This presents a point of tension between the wishes of people with intellectual disabilities and their families as recent research findings have indicated that when asked about their aspirations, people with intellectual disabilities in Ireland, described how they wish to become a partner in a relationship (Garcia-Iriarte et al. 2013).

The loneliness family caregivers felt, and the feeling of having little or no life for themselves were also expressed, due to the all encompassing nature of the care giving experience. People spoke about the difficulties balancing work and the carer role and the loss of the valued social role they had when they had a career. Other negative aspects of life mentioned were shame, stigma, being overwhelmed and feeling isolated, alone and exhausted, as this extract from a focus group transcript illustrates.

M1: "Yeah but you can get downhearted at times. Every one has spent nights crying."

M2: "You can feel very alone, you could feel very, very lonely."

M1: "The biggest injustice to me is that you don't have any life."

M3: "but you do sometimes feel nearly a duty to the rest of the world to be positive. To put on a positive face." (Mothers, Wexford)

Families spoke too of their concerns about the future; they spoke about what would happen to their family member after they had died or if circumstances changed and they were no longer able to support them. They wanted their family member to be happy and settled under such circumstances. Many worried about who would provide care and whether siblings would take on the carer role.

"... we have all the concerns that people have, what happens when we move on (Die)." (Father, Dublin)

\section{Support and advocacy}

Families spoke a great deal about the supports they and their family member with intellectual disabilities received from services, professionals, family members, friends and other parents and how they had to fight for things for their family and to advocate for their family member with intellectual disabilities. Having a family member with intellectual disabilities led families to enter a system of supports and entitlements that could be extremely challenging at times.

"The biggest difficulty is the fact that you're thrown into this system when your child is born and nothing prepares you for the system that you end up in." (Mother, Louth)

Families accessed a wide range of services: including residential, day, employment, education, training, therapy and respite breaks. The quality of the services appeared to be judged on the perceived appropriateness, quantity and the opportunities afforded by services to the family. Families praised services that they believed supported their family in appropriate ways. For families, 'appropriate' meant services where staff were committed and inspiring, and that were provided in a timely, well co-ordinated, flexible manner and which were responsive to the family's changing needs.

They wanted person-centred services that gave their family member choice and control over their lives but that also balanced their rights and responsibilities appropriately. Families spoke about wanting services that offered opportunities for their family member and that listened to and respected their wishes. Related to this they also described the tension that exists between these aspirations and the need to protect their family member so that they felt sure they were well looked after and unlikely to come to any harm.

"... we wondered about all those things (whilst the family member was in residential services), wouldn't you? Knowing their safe" (Father, Cork)

"now they're focussing on each individual and it's what they want to do and if they can facilitate that they will" (Sister, Kilkenny)

They sought developmental opportunities for their relative and for them to be occupied during the day, be that at college, a day centre, in the community or in a job. Others commented that being equipped with the 
prerequisite skills was essential prior to a more independent residential placement and life. Ultimately, they wanted their family member with intellectual disabilities to be well cared so that they were getting the best out of life.

"we constantly say he's capable of more." (Mother, Dublin)

Many families reported receiving good support from family and friends although some told the group how support from families developed or diminished over time. Alongside these families sometimes spoke about their family member wanting more independence and autonomy as they grew older.

"... there was a lot of support from family ... but when he got older and when he became more challenging, he didn't want to be babysat ... he wanted to go out and he wanted to do his own thing." (Mother, Mayo)

Families spoke about parents working together in both formal and informal networks and support groups. They concurred on how these networks provided support to families and may be more effective at lobbying government and services for change. However, some parents commented that the necessary commitment from families for such networks and groups was not always given.

"I'm disappointed that you invited ten people here today, there's only six turned up. That to me is typical of what parents are, so lethargic and careless, the majority of them." (Father, Clare)

Families spoke at length about the poor support that they had experienced from services. Some commented on the lack of services available, in particular respite, home based and therapeutic support services. This lack led to limited or no choice of services for families. Some spoke about services being primarily reactive and only getting the services they needed when the family was at 'breaking point'. Getting timely services that were well co-ordinated, flexible and responsive was also problematic for some families.

"Well my son was diagnosed at two and a half ... And, it (the referral) had to go through the process of the HSE [Health Services Executive], and then to the (Service name), who both of them had waiting lists. So two years later, my son still didn't have a service." (Mother, Clare)
Although rarely directly mentioned, acting as an advocate underpinned much of what family caregivers spoke about, and this occurred across the lifespan of the carers in the focus groups. Three main advocacy activities were discussed: (i) trying to raise awareness and improve attitudes amongst community members, service and governmental staff and in wider society; (ii) contacting and checking services to ensure they were doing the best for their family member with intellectual disabilities and (iii) the fighting families had to do to access and get better services for their family. The latter was most often discussed.

"Our experience has been that anything that we got we had to agitate ... it's extraordinary the difficulty that we had trying to get any sort of a service." (Father, Louth)

There was the belief amongst many family carers that no one else would fight for them or their families and so they had to do it. Yet they felt that they shouldn't have to fight for basic rights for their children: services should be provided based on equity and need. Fighting wasn't a route taken by all parents. Feelings of being thankful for what you have and a belief that one shouldn't complain led some family carers not to advocate for more. Others didn't advocate because they feared that fighting for services and complaining about services may lead to service loss or to negative repercussions for their family member. Some focus group participants spoke specifically about older families not wishing to rock the boat having accepted the status quo of service provision as it currently stood.

"I always feared that if I made complaints or was dissatisfied or anything like that, that service could be pulled." (Mother, Mayo)

"If we say something to the service you always feel that there might be a backlash on the child." (Mother, Dublin)

Tenacity was evident in many of the advocacy stories recounted by parents. Some of the older carers had fought for services and to get a better deal for their family for many decades. However, the ability to advocate and fight waned over time as parents became exhausted, aged and became more accepting of their circumstances. Family members also talked about how difficult it was to fight whilst caring for their family member.

F: "As you get older, you get softer, right." 
M: "Well you don't have the strength." (Father, Mother, Mayo)

The impact that fighting for services had upon other families included frustration, anger, resignation, exhaustion and household stress amongst family members. Positive outcomes of fighting and advocating included getting the changes and additional services desired and benefiting other people because previous successful fighting set some sort of precedent within the organization.

\section{Communication and accessing information}

All the focus groups mentioned the interrelationships between services and families, which were described as both positive and negative. Families spoke of the excellent communication and passion of staff working in different types of services. Respectful communication appeared fundamental to success.

"I think first of all they're genuinely interested in what they're doing and they want to make that person happy in their environment, so that one's very important. Secondly they are good listeners, and they're also good talkers. They tell you what's been happening." (Father, Dublin)

More negative reports were given about how service staff communicated when services were unavailable and that families were sometimes made to feel ungrateful and that they should appreciate what they had.

"I did try to argue with it and was told there was no options and that there was also people much worse off than myself." (Mother, Kildare)

Many families discussed the inconsiderate and insensitive way service staff had communicated with them. They felt that services should provide information about their relative in a sensitive manner and should not be unfeeling when talking about their family member.

“... we didn't know K was Down syndrome before she was born and his (doctor's) reaction ... frightened us ... by the way he responded we thought she was going to be the worst of the worst. It was all very negative. Nothing was positive when she was born." (Mother, Kilkenny)
Families talked about not feeling included, involved and consulted. They described instances where they had not being kept abreast of what was happening in the life of their family member, where decisions had been made without their input. Some spoke about being experts about their children and that this expertise was ignored. Services were also criticized for not listening to families or acknowledging their worries and concerns.

"parents ... should be listened to. No-one knows their children better than we do." (Mother, Mayo)

Lack of consultation and involvement seemed to happen more when their child entered adult services. Families felt that services and families should have more open, ongoing two-way communication. Some voiced the opinion that it is important that services are trustworthy, indicating they did not always trust services.

"I think when they get older... service providers tend to take over a bit more because they want them to have independent living skills which is fantastic ... and you are sort of left out in the cold a little bit." (Mother, Cork)

The lack of communication extended to how services treated their family members. Instances were described where service staff had implemented interventions or changes without getting to know and building a rapport with the person with intellectual disabilities or their family.

"And I couldn't believe how much they weren't aware (of) the things he could do that we knew he could do." (Mother, Kildare)

They highlighted how important it was to them for services to treat their family member respectfully, acknowledging their need for privacy and their uniqueness as an individual.

"But a positive thing ... about where he's going, they bend over backwards. They have the person centred plan and they want to know what you think, what he thinks, what I think." (Mother, Kilkenny)

Lack of information about entitlements, eligibility, services and supports was difficult for many of the families. Information was needed about: (i) where to get information from; (ii) their family member's intellectual disability and current and ongoing support needs; 
(iii) support groups; (iv) available services, what they are like and what they offer; (v) funding, benefits and other entitlements and (vi) eligibility information.

“... people ... can't get accurate information. They can't obtain it. So, that information is hidden. It's about funds, it's about the rights, it's about the services." (Mother, Cork)

Some families expected services to provide all this information or to be able to direct families to where they could get hold of it. Many commented that they got information by chance from other parents and from specific and generic support organizations. Few mentioned getting information from services and medical professionals. There was a feeling that services kept information hidden from them and that they should make information more readily available and transparent. Some spoke about passing information on to other parents and the need to recognize that some families cannot access the Internet.

"Access to information is a huge problem because most of the information that we access would have been through making a lot more noise ... and accidentally meeting somebody." (Father, Cork)

\section{Attitudes and governance}

The manifest attitudes of service staff, professionals, politicians, family and friends, local communities and wider society impacted on the lives of families. Families spoke about various positive and negative attitudes that they had experienced towards their family. Historically, a number of parents and siblings gave historical accounts, indicating that societal attitudes had improved, with less stigma and shame attached to having a family member with intellectual disabilities.

Nevertheless, families continued to report how members of the public behaved in an awkward, scared or embarrassed manner around people with intellectual disabilities and described instances where people with intellectual disabilities were avoided or excluded.

"there is something I think about mental handicaps that frightens people an awful lot." (Mother, Wexford)

Politicians and government officials also appeared indifferent to disability. Families felt that people with disabilities were an ignored group whose needs were seen as unimportant.
"So they're writing off your children. They're not trying to give them an educational option or an employment option, they're just writing them off; oh they're disabled, they don't figure." (Mother, Louth)

Lack of societal awareness of disabilities and of the challenges families face supporting a family member with intellectual disabilities were both reported. This was particularly evident when their family member did not have any physical signs that they had intellectual disabilities and were viewed as unruly or difficult, resulting in people thinking carers had poor parenting skills.

"Again my son looks perfectly normal, and from an early age you heard stuff like 'oh he's a bold little brat."

(Mother, Clare)

Others described situations where their family member was viewed as angelic and where they had been patronized by others. Family members also expressed the wish that society recognize that people with intellectual disabilities should not be made fun of.

"I suppose my biggest one would be for people of our country to recognise special needs ... and that they shouldn't be made fun of, and parents should teach their children to be a bit more tolerant." (Mother, Mayo)

Negative attitudes, particularly those resulting in the family member being excluded, ignored, bullied or made fun of, upset family carers.

M: "... you can't imagine what it's like. I live in a small village, To see her walk out alone and nobody speaks to her."

F: "It's the biggest single hurt to parents across everything is the fact that their child is not acknowledged." (Mother, Father, Mayo)

Conversely though, families also spoke about the positive attitudes and experiences they had had where people had said that contact with their family member with intellectual disabilities was an enriching experience for young people.

"other parents from her class would come up to us, and say I'm so delighted your daughter is in our class, because it's enhanced our child's life and behaviour." (Father, Dublin) 
Families linked societal attitudes with the implementation of policies in services, aspects of governmental support and funding issues they had faced in Ireland when caring for their family member. Governmental bodies and services were described as failing to follow through on or to implement policies.

"there was a proposal that every person with disabilities would have a life plan ... And that ... the appropriate services would become available to them at the appropriate times. When this was brought in we felt this was a great thing. But in actual fact, we never, never heard any more about it after that." (Father, Louth)

Families spoke about their frustrations with government and services system bureaucracies in trying to access necessary funding and supports, especially when different government organizations 'pass the buck'. Families talked about this in two ways. First, experiences where they had tried to access funding and supports by contacting government bodies and services and had been told that they had contacted the wrong place. They were then passed to another agency, which in turn claimed that helping the family with this issue is not their responsibility either. Second, they also described situations where the agencies refusing funding or services to families attributed responsibility to another agency. These situations were sometimes described in conjunction with other themes, namely, difficulties families had accessing information and frustrations they experienced fighting for services.

The 'top-down' way the governmental organizations worked was also mentioned, where decisions are made with little thought given to the actual impact these would have on people's lives. The government was also said to be failing to meet the raised expectations of parents and people with intellectual disabilities. Families appreciated the importance of lobbying Government and getting politicians on side.

"... health service is built from the top so when you get to the bottom there's nothing. There's no money. Instead of building it from the floor, you build it from the patients and people with disabilities. You build around them and then you work your way up. We don't." (Father, Louth)

Some participants felt that money was not spent appropriately by services and that there was insufficient spending on direct care and support and too much on management staff. Some family members wanted more information about, and more control over, how the money allotted to their family member was spent. Individualized funding was mentioned as potentially providing more control to people with intellectual disabilities and their families. Others said they wanted to know more about the different ways that funding could be allocated.

"Yeah I think parents should have more input into what's happening with the money and where it's going. And have more say in what the child could be doing." (Mother, Cork)

\section{Reflections on family members as co-researchers}

Family members who acted as co-researchers helped with the recruitment of participants and co-facilitated focus groups, as well as acting as ongoing research advisors during interpretation of the data and the disseminating of findings. This involvement aimed to give greater ownership of the research to the family coresearchers (Turnbull et al. 1998) and to lead to the gathering of knowledge that could be of use to families in their everyday lives (Reason \& Bradbury 2006). The research team reflected on the feasibility and impact of including family members as co-researcher and concluded that this process appears to have provided a number of benefits to the research, and to the family and university co-researchers (see Walmsley \& Mannan 2009 for fuller details). It allowed participants in focus groups more freedom of expression through the family coresearchers speaking of their own circumstances. University co-researchers felt more sure of the relevance of the research findings because of the family involvement and input. Family co-researchers helped select convenient times and locations for parents reducing logistical problems. There was also some limited evidence that family co-researchers felt empowered by the training, the networking, their participation in the focus groups and through their involvement in dissemination of the findings to services. Family and university co-researchers both felt the participatory element was worthwhile but also saw the need for service providers to be involved in future dialogues with carers if changes in practice were to happen.

\section{Discussion}

The main aim of this study was to capture the dominant themes in the life experiences of family carers of people 
with intellectual disabilities in Ireland. Although the participants did form a self-selected group and their responses may not be representative of all Irish carers, the four organizing themes that were identified echo those reported in previous research investigating family life experiences and factors that influence wellbeing. In particular, gaining access to adequate and appropriate supports, services, information and resources for the family, the difficulties in relationships and communication between families and services and professionals; and the need to advocate and fight for services (e.g. Summers et al. 2007; Power 2008; Yannamani et al. 2009).

However these findings also identified the complexities and challenges that family carers face. Most fundamentally this comes from the dynamic nature of the caring process and how their life can be a series of 'ups and downs' with the need for continual adaptations. Some of the changes are predictable and arise at major life transitions for their relative yet any change can be very unsettling; affecting the ongoing well-being of the whole family.

Hence families have to balance the positive and negative aspects of care-giving which is consistent with the two-factor model of care giving (Lawton et al. 1991) previously noted in studies of parents of adults with intellectual disabilities (Pruchno et al. 1996; Smith 1996). The resulting emotional stress experienced by carers that is well documented in the literature (e.g. Browne \& Bramston 1998; Hoare et al. 1998) may then find expression in their advocacy for better supports and influence the nature of the relationships they forge with services and their perceptions of societal attitudes.

Equally the findings confirm a duality among parents' responses to the stress of caring. On the one hand, the 'wear and tear' hypothesis (Birenbaum 1971; Grant \& Ramcharan 2001) predicts that family coping becomes more difficult as the family member with intellectual disabilities ages and as families tire over time, and links constant advocacy and fighting for services and supports as a potential exacerbating factor in the process of 'wear and tear'. By contrast, other families appear to have adapted across the lifespan, lending indirect support to the 'adaptation' hypothesis (Seltzer \& Krauss 1989; Grant 1993), which suggests that people adjust to caregiving over time, acquiring skills that help them to cope better.

It may also be that the tenacity exhibited by family members whilst advocating becomes a fundamental aspect of their identity, with such identity being an influential factor in the life and future well-being of the family member with intellectual disabilities. It may also map onto factors such as family resilience, feelings of self-efficacy and burnout in family carers. These hypotheses could be usefully explored in future studies. A lifespan approach to family support and well-being also requires future research to take a longitudinal perspective (Families Special Interest Research Group of IASSID 2012). Such research could determine if families do fight less and accept more as they age. It could also explore the troubling comment made by some parents that, despite financial and programmatic interventions, things remain the same for them and have not improved. The similarity between the findings here and older research findings provides indirect evidence for this.

This study did not identify aspects of the caregiving experience of families that were particularly unique to Ireland. One such aspect that was not explored here, is the distinctions in family experience between those who gain services from statutory versus voluntary service providers. The Roman Catholic ideology underpinning may voluntary sector services within Ireland and may help to explain the finding that families felt they should be grateful for what they received from services and reluctant to complain. Again this is a question for future studies.

Throughout all of the focus group discussions mention was made by carers that they did not feel valued or respected by some service personnel and officials who showed little understanding of their feelings and aspirations. The study identified various forms of support that families require in order to maintain their caring role across the lifespan. This included: (i) more appropriate, flexible and timely support for families at critical times throughout their family's life; (ii) to be offered services, support, entitlements and information without having to fight all the time, and to be free to complain without fear; (iii) to know that their family member with intellectual disabilities is well cared for, listened to and provided with opportunities to develop and be part of the community; (iv) to be shown respect, to be listened to and involved in decisions by services and professionals.

Despite the negative aspects of life reported by families, the findings regarding the positive aspects of having a family member with intellectual disabilities were also corroborated in the reports of the Irish families (e.g. Ylvén et al. 2006; Green 2007) as well as accounts of good supports from services (Merriman \& Canavan 2007). 
A unique aspect of this study was the inclusion of family carers as co-researchers. This proved to be a feasible strategy with many more family members volunteering to participate in training than expected, and although smaller numbers decided to co-facilitate the focus groups, their contribution did create a sense of the research being carried out with families rather than to them. They also contributed to the data analysis and to the planning and implementation of subsequent studies. Their involvement in presenting the findings to local groups has also proved very effective in promoting carer-advocacy to families. These experiences also further confirmed the value of other training opportunities for family carers; particularly joint training of service staff and families to provide better continuity of support for the family member with intellectual disabilities. Two further studies have been completed which also included families as co-researchers. First a national survey of over 500 family carers in Ireland (Chadwick et al. 2010) and second an investigation into the perceptions and experiences of service personnel in working with family carers (Chadwick et al. 2012). Together these aim to provide a better understanding between family carers and service personnel.

Families are unique in their personalities, structures, dynamics and propensity for adaptation. By listening to families, working and building better relationships with them, and meeting their needs, the challenges families face may be alleviated rather than exacerbated. Policy makers, service providers and the wider community in Ireland and internationally should work more closely with families to address these needs to enable people with intellectual disabilities and their families to feel supported, empowered, included and afforded their basic human rights.

\section{Acknowledgments}

This research was funded by a Marie Curie Transfer of Knowledge Fellowship to the National Institute for Intellectual Disability, Trinity College Dublin, within the 6th European Community Framework Programme. The views expressed herein are those of the authors and not necessarily those of the 6th European Community Framework Programme. The authors would like to thank Professor Seamus Hegarty for commenting on early drafts of this paper, the European Union Marie Curie Transfer of Knowledge Framework 6 Programme that funded this research project and all the family carers who gave so freely of their time to take part in the focus groups.

\section{Correspondence}

Any correspondence should be directed to Darren D. Chadwick, School of Applied Sciences, The University of Wolverhampton, MC Block, Wulfruna Street, Wolverhampton WV1 1L, UK (e-mail: d.chadwick@wlv. ac.uk).

\section{References}

Baker B. L., Blacher J. \& Olsson M. B. (2005) Preschool children with and without developmental delay: behavioural problems, parents' optimism and well being. Journal of Intellectual Disability Research 49, 575-590.

Beresford B. (1995) Expert Opinions: A National Survey of Parents Caring for a Severely Disabled Child. Joseph Rowntree Foundation and Policy Press, York and Bristol.

Birenbaum A. (1971) The mentally retarded child in the home and the family cycle. Journal of Health and Social Behaviour 12, 55-65.

Blacher J. \& Baker B. L. (eds) (2002) The Best of AAMR: Families and Mental Retardation: A Collection of Notable AAMR Journal Articles Across the 20th Century. American Association on Mental Retardation, Washington, DC.

Braun V. \& Clarke V. (2006) Using thematic analysis in psychology. Qualitative Research in Psychology 3, 77-101.

Browne G. \& Bramston P. (1998) Stress and the quality of life in the parents of young people with intellectual disabilities. Journal of Psychiatry and Mental Health Nursing 5, 415-421.

Chadwick D. D., Finlay F., García Iriarte E., Greene S., Harrington J., Lawlor A., Mannan H., McConkey R., O'Brien P., Spain J. \& Turner A. (2010) Family Voices: Life in Ireland For Families of People with Intellectual Disabilities. National Institute for Intellectual Disabilities, Trinity College Dublin, Dublin.

Chadwick D. D., McConkey R., Iriarte Garcia E., O'Brien P., Finlay F., Greene S., Lawlor A. \& Spain J. (2012) FamilyService partnerships: exploring collaboration between families of people with intellectual disabilities and those working in services. A World of Potential, 14th IASSID World Congress, Halifax, Nova Scotia, Canada, 9th-14th July, 2012.

Dobson B., Middleton S. \& Beardsworth A. (2001) The Impact of Childhood Disability on Family Life. Joseph Rowntree Foundation, York.

Families Special Interest Research Group of IASSID (2012) Families Supporting a Child with Intellectual or Developmental Disabilities: The Current State of Knowledge. IASSID. Available at: https://iassid.org/images/documents/SIRGs/Families/ families_sirg_position_paper_final.pdf (accessed on 19 July 2012).

Fergusson P. \& O'Brien P. (2005) From giving service to being of service. In: Allies in Emancipation: Shifting from Providing 
Service to Being of Support (eds P. O'Brien \& M. Sullivan), pp. 3-18. Dunmore Press, Victoria.

Glidden L. M. \& Jobe B. (2006) The longitudinal course of depression in adoptive and birth mothers of children with intellectual disabilities. Journal of Policy and Practice in Intellectual Disabilities 3, 139-142.

Grant G. (1993) Support networks and transitions over two years among adults with a mental handicap. Mental Handicap Research 6, 36-55.

Grant G. \& Ramcharan P. (2001) Views and experiences of people with intellectual disabilities and their families: the family perspective. Journal of Applied Research in Intellectual Disabilities 14, 364-380.

Green S. E. (2007) "We're tired, not sad": benefits and burdens of mothering a child with a disability. Social Science $\mathcal{E}$ Medicine 64, 150-163.

Halpern E. S. (1983) Auditing Naturalistic Inquires: The Development and Application of a Model. Doctoral Thesis, Indiana University, Indiana, USA.

Hastings R. P. \& Taunt H. M. (2002) Positive perception in families of children with developmental disabilities. American Journal on Mental Retardation 107, 116-127.

Health Services Executive (2012) Regional service plans 2012. Available at: http://www.hse.ie/eng/services/Publications/ corporate/regionalserviceplans2012.html (accessed on 1 June 2012).

Hoare P., Harris M., Jackson P. \& Kerley S. (1998) A community survey of children with severe intellectual disability and their families: psychological adjustment, carer distress and the effect of respite care. Journal of Intellectual Disability Research 42, 218-227.

Garcia-Iriarte E., O'Brien P. \& Chadwick D. (2013) What have we learned about doing research with people with intellectual disabilities?: reflection on three studies conducted in the island of Ireland. Journal of Policy and Practice in Intellectual Disability, in press.

Kelly F. \& McConkey R. (2012) Changes in the provision of residential care for adult persons with an intellectual disability: a national longitudinal study. Tizard Learning Disability Review 17, 4-10.

Kelly C., Craig S. \& Kelly F. (2010) HRB Statistics Series 8: Annual Report of the National Intellectual Disability Database Committee 2009. HRB, Dublin, Ireland.

Kenny K. \& McGilloway S. (2007) Caring for children with learning disabilities: an exploratory study of parental strain and coping. British Journal of Learning Disabilities, 35, 221-228.

Ladkin D. (2007) Action research. In: Qualitative Research Practice (eds C. Seale, G. Gobo, J. F. Gubrium \& D. Silverman), pp. 478-490. Sage Publications Ltd, London.

Lambrenos K., Weindling A. M., Calam R. \& Cox A. D. (1996) The effect of a child's disability on mother's mental health. Archives of Disease in Childhood 74, 115-120.

Lawton M. P., Moss M., Kleban M. H., Glicksman A. \& Rovine M. (1991) A two-factor model of caregiving appraisal and psychological well-being. Journalof Gerontology: Psychological Sciences 46, 181-189.

Lincoln Y. S. \& Guba E. G. (1985) Naturalistic Enquiry. Sage, USA.

McConkey R. (2005) Fair shares? Supporting families caring for adult persons with intellectual disabilities. Journal of Intellectual Disability Research 49, 600-612.

McConkey R., Kelly F., Mannan H. \& Craig S. (2010) Inequalities in respite service provision: insights from a national, longitudinal study of people with intellectual disabilities. Journal of Applied Research in Intellectual Disabilities 23, 85-94.

McTaggart R. (1991) Principles for participatory action research. Adult Education Quarterly 41, 168-187.

Merriman B. \& Canavan J. (2007) Towards Best Practice in the Provision of Respite Services for People with Intellectual Disabilities and Autism. HSE/NUI Galway/National Parents and Siblings Alliance/Daisychain Foundation, Galway, Ireland.

NVivo qualitative data analysis software (2008) QSR International Pty Ltd. Version 8.

Olsson M. B. \& Hwang C. P. (2001) Depression in mothers and fathers of children with intellectual disability. Journal of Intellectual Disability Research 45, 535-543.

Olsson M. B., Larsman P. \& Hwang C. P. (2008) The relation between risk, sense of coherence and well-being in parents of children with and without intellectual disabilities. Journal of Policy and Practice in Intellectual Disability 5, 227-236.

Poston D. J., Turnbull A. P., Park J., Mannan H., Marquis J. \& Wang M. (2003) Family quality of life outcomes: a qualitative inquiry launching a long-term research program. Mental Retardation 41, 313-328.

Power A. (2008) 'It's the system working for the system': carers' experiences of learning disability services in Ireland. Health and Social care in the Community 17, 92-98.

Pruchno R. A., Patrick J. H. \& Burant C. J. (1996) Mental health of aging women with children who are chronically disabled: examination of a two-factor model. Journal of Gerontology: Social Sciences 51B, S284-S296.

Reason P. \& Bradbury H. (2006) Handbook of Action Research: The Concise, paperback edn. Sage, London.

Sardi I., Northway R., Jenkins R., Davies R. \& Mansell I. (2008) Family carers' opinions on learning disability services. Nursing Times 104, 30-31.

Scorgie K. \& Sobsey D. (2000) Transformational outcomes associated with parenting children who have disabilities. Mental Retardation 38, 195-206.

Seltzer M. M. \& Krauss M. W. (1989) Ageing parents with mentally retarded children: family risk factors and sources of support. American Journal on Mental Retardation 94, 303312.

Shearn J. \& Todd S. (1997) Parental work: an account of the day to day activities of parents of adults with learning disabilities. Journal of Intellectual Disability Research 41, 285-301. 
Shenton A. K. (2004) Strategies for ensuring trustworthiness in qualitative research projects. Education for Information 22, 63-75.

Sloper T. \& Beresford B. (2006) Families with disabled children. British Medical Journal 333, 928-929.

Smith G. C. (1996) Caregiving outcomes for older mothers of adults with mental retardation: a test of the two-factor model of psychological well-being. Psychology and Aging 11, 353-361.

Summers J. A., Marquis J., Mannan H., Turnbull A. P., Fleming K., Poston D. J., Wang M. \& Kupzyk K. (2007) Relationship of perceived adequacy of services, family-professional partnerships, and family quality of life in early childhood service programmes. International Journal of Disability, Development \& Education 54, 319-338.

Turnbull A. P., Friesen B. J. \& Ramirez C. (1998) Participatory action research as a model for conducting family research.
Journal of the Association of Persons with Severe Handicaps 23, 178-188.

Walmsley J. \& Mannan H. (2009) Parents as co-researchers: a participatory action research initiative involving parents of people with intellectual disabilities in Ireland. British Journal of Learning Disabilities 37, 271-276.

Welshman J., Nind M. \& Rolph S. (2005) General introduction. In: Witnesses to Change: Families, Learning Difficulties and History (eds S. Rolph, D. Atkinson, M. Nind \& J. Welshman), pp. 11-32. BILD, Glasgow.

Yannamani N., Zia A. \& Khalil N. (2009) Family carers of people with learning disabilities: common themes across caring. Psychiatry 8, 441-444.

Ylvén R., Björck-Akesson E. \& Grandlund G. M. (2006) Literature review of positive functioning in families with children with a disability. Journal of Policy and Practice in Intellectual Disabilities 3, 253-270. 
Copyright of Journal of Applied Research in Intellectual Disabilities is the property of Wiley-Blackwell and its content may not be copied or emailed to multiple sites or posted to a listserv without the copyright holder's express written permission. However, users may print, download, or email articles for individual use. 